\section{Leading Up to the Pencil}

The pencil-a graphite-filled wooden rod-was introduced as a writing instrument more than four centuries ago. Unlike implements that use ink or other liquid writing media, the pencil employs a solid marking substance. And its very simplicity, efficiency, and low cost have allowed it to remain one of the most commonly used writing instruments despite such technologically advanced alternatives such as the ball-point pen, the typewriter, and the computer.

In 1564 a large deposit of a new mineral was discovered in a mine at Borrowdale, Cumberland, in England's Lake District. The discovery was supposedly made when a storm uprooted a large oak tree. This new mineral was found in soft, lustrous veins. Thought to be a form of lead, it was called "black lead" or "plumbago."

Black lead made a dark but removable mark, blacker than metallic lead. Metallic lead had been used since Roman times and had remained one of the most common alternatives to marking on paper because the quill and ink method was so bothersome.

Black lead was first used in chunks, called marking stones. Later, the material was cut into small rods or strips and wrapped in twine to provide a comfortable grip and additional strength. Users unwound the twine from the point, as necessary. These instruments made a fine black line, reminiscent of the writing from the fine Roman brush called a pencilium; thus the instrument became known as a lead pencil. The German word for pencil, Bleistift, literally means "lead pin."

Since black lead was also found to have many important military applications-it was, for instance, added to iron in the casting of cannon balls-output from the Borrowdale mine was closely guarded and regulated, which meant that even small amounts of black lead were very difficult to come by.

In 1565 the German-Swiss naturalist Konrad von Gesner first wrote about a new writing instrument composed of a chip of black lead inserted into a wooden holder. This method not only kept a writer's fingers from getting smeared, but also prevented the expensive black lead from breaking.

Von Gesner described black lead as a new and separate mineral, which he called stimmi anglicanum or English anti- mony. Not until 1779 did Carl Wilhelm Scheele, a chemist in Sweden, recognize black lead to be a form of microcrystalline carbon. In 1789 Abraham G. Werner named the substance "graphite" after the Greek word qraphien, meaning "to write."

Though the English supply of graphite was pure enough to be used in its natural state, other countries sought viable alternatives, binding graphite dust (waste and residue from the mines) into usable shapes with glues, gums, or resins. The first graphite-composition pencil was made in 1662 in Nürnberg, Germany, by Kaspar Faber. He found that a mixture of two parts graphite dust to one part sulfur came closest to the writing properties of pure graphite.

During the Napoleonic Wars in the late 18th century, the French were unable to obtain supplies of graphite from England. One of Napoleon's engineers, Nicolas-Jacques Conté, was charged with finding a way to make good pencils out of poor graphite. He found that he could use thin rods made of pulverized graphite mixed with powdered clay and water; he pressed the pasty mixture into wooden molds, then fired them. These pencils, also called conté crayons, were more uniform and reliable than natural graphite pencils.

The hardness of the pencil lead could alsc be varied by altering the amount of clay in the mix. Conte is the creator of the numerical designation of "hardness" still used for pencil leads (no relation to the Mohs scale). The hardness scale for pencil lead is actually a measure of how much the pencil lead resists abrasion by the fibers of the paper. Since we actually read the debris, the success of pencils depended on finding graphite or graphite/clay mixtures with appropriate wear properties. Graphite leaves behind a nice trail of debris because the weak bonds between the layers allow the layers to slide apart easily. The darkness of a pencil mark is related to the size and number of wear particles deposited by the pencil. The more graphite in the mix, the blacker and "softer" the pencil lead.

Henry David Thoreau's father was one of the earliest pencil makers in the United States. The Thoreaus improved the Conté process so that by the mid1840 s Thoreau pencils were the best made in the United States. However, less-expensive German pencils, particu- larly those from the firm of A.W. Faber flooded the market.

Most wooden pencil casings were made of cedar, though some later casings were made of plastic, metal, or resin/ sawdust composites.

Sharpening pencils became a noticeable nuisance to the many users as early as 1822 . This led to numerous inventions and variations on the "mechanical pencil," a contrivance that mechanically feeds an uncased stick of graphite to the writing tip.

The idea of attaching an eraser directly to the pencil body was patented in 1858 by an American, Hyman W. Lipman, who sold his patent 14 years later to Joseph Rechendorfer for the then exorbitant sum of $\$ 100,000$.

"Colored pencils" were made possible by replacing the black graphite entirely with either water-soluble or water- insoluble pigments or dyes mixed with filler (usually clays or talc), lubricant, and possibly other binders, and then fired.

By the middle of the 19th century, after about 300 years, the English graphite mines were finally played out, but an equally rich and pure source was discovered in Asia. The A.W. Faber firm gained exclusive rights to this deposit.

Yellow-painted Faber pencils made with Siberian graphite were so popular they became the world standard. Competing manufacturers painted their brands yellow and named them "Mongol" and "Mikado" to imply that they, too, came from Asia.

In the United States, in Texas, another major graphite deposit was found. But then in 1896, inventor Edward G. Acheson created a process for making graphite directly from coke. Virtually all U.S.-made pencils now use manufactured graphite instead of the natural form!

Special pencils have also been designed. Rectangular or square carpenters' pencils do not roll if dropped and are also designed to be easily used with a straight-edge. Electronic grading of standardized tests has been facilitated by using pencil lead that conducts electricity (No. 2 pencils).

KEVIN J. ANDERSON

FOR FURTHER READING: Clarence Fleming and A.L. Guptil, The Pencil Since 1565 (1936), and Joyce J. Walley, Writing Implements and Accessories (1975). 